Research Article

\title{
Chinese Herbal Medicines for Rheumatoid Arthritis: Text-Mining the Classical Literature for Potentially Effective Natural Products
}

\author{
Xuan Xia $\mathbb{D}^{1},{ }^{1,2}$ Brian H. May $\mathbb{D}^{3},{ }^{3}$ Anthony Lin Zhang $\mathbb{D}^{3},{ }^{3}$ Xinfeng Guo $\mathbb{D}^{1},{ }^{1}$ Chuanjian Lu, ${ }^{1}$ \\ Charlie C. Xue $\left(\mathbb{1},{ }^{3}\right.$ and Qingchun Huang $\mathbb{B}^{1,2}$ \\ ${ }^{1}$ The Second Clinical College of Guangzhou University of Chinese Medicine, No. 111, Dade Road, Yuexiu District, \\ Guangzhou 510120, China \\ ${ }^{2}$ Department of Rheumatology and Immunology, Guangdong Provincial Hospital of Chinese Medicine, No. 55, Neihuanxi Road, \\ Higher Education Mega Center, Guangzhou 510006, China \\ ${ }^{3}$ China-Australia International Research Centre for Chinese Medicine, RMIT University, P.O. Box 71, Bundoora, \\ Victoria 3083, Australia
}

Correspondence should be addressed to Charlie C. Xue; charlie.xue@rmit.edu.au and Qingchun Huang; qch1963@163.com

Received 14 January 2020; Accepted 9 March 2020; Published 29 April 2020

Academic Editor: Antonella Fioravanti

Copyright (c) 2020 Xuan Xia et al. This is an open access article distributed under the Creative Commons Attribution License, which permits unrestricted use, distribution, and reproduction in any medium, provided the original work is properly cited.

Background. Rheumatoid arthritis (RA) is an autoimmune disease characterized by multijoint swelling, pain, and destruction of the synovial joints. Treatments are available but new therapies are still required. One source of new therapies is natural products, including herbs used in traditional medicines. In China and neighbouring countries, natural products have been used throughout recorded history and are still in use for RA and its symptoms. This study used text-mining of a database of classical Chinese medical books to identify candidates for future clinical and experimental investigations of therapeutics for RA. Methods. The database Encyclopaedia of Traditional Chinese Medicine (Zhong Hua Yi Dian) includes the full texts of over 1,150 classical books. Eight traditional terms were searched. All citations were assessed for relevance to RA. Results and Conclusions. After removal of duplications, 3,174 citations were considered. After applying the exclusion and inclusion criteria, 548 citations of traditional formulas were included. These derived from 138 books written from 206 CE to 1948. These formulas included 5,018 ingredients (mean, 9 ingredients/formula) comprising 243 different natural products. When these text-mining results were compared to the 18 formulas recommended in a modern Chinese Medicine clinical practice guideline, $44 \%$ of the herbal formulas were the same. This suggests considerable continuity in the clinical application of these herbs between classical and modern Chinese medicine practice. Of the 15 herbs most frequently used as ingredients of the classical formulas, all have received research attention, and all have been reported to have anti-inflammatory effects. Two of these 15 herbs have already been developed into new anti-RA therapeutics-sinomenine from Sinomenium acutum (Thunb.) Rehd. \& Wils and total glucosides of peony from Paeonia lactiflora Pall. Nevertheless, there remains considerable scope for further research. This text-mining approach was effective in identifying multiple natural product candidates for future research.

\section{Introduction}

Rheumatoid arthritis (RA) is a chronic inflammatory autoimmune disease characterized by multijoint swelling and pain and destruction of the synovial joints, leading to severe disability and increased mortality [1-3]. The global prevalence was estimated at $0.24 \%$ but it is higher in some populations [4], with $0.5-1 \%$ of adults in the United States being affected [5]. Over the last decade, the optimal use of disease modifying antirheumatic drugs (DMARDs) $[6,7]$ and the increasing availability of new biological agents $[8,9]$ have enhanced the success of RA management. Traditional treatment methods are widely used in China often in combination with DMARDs and/or biologics [10]. This is 
likely due to a combination of concerns about the side effects of DMARD combination therapy, the high cost of biological agents in China, the ready availability of traditional treatments in the hospital system [11], and public awareness of the increasing literature on the evidence base for traditional treatments such as herbal formulations and acupuncture [12-16].

Clinical guidelines for prescribing traditional medicines for RA provide criteria for differentiating the Chinese medicine syndromes and selecting appropriate multi-ingredient formulations which are typically administered in the form of decoctions, granules, capsules, and pills [17]. In addition, manufactured medicines based on extracts of plants used traditionally for joint pain have been developed and evaluated in clinical trials $[18,19]$.

Along with the increasing application of clinical trial methodologies for the evaluation of traditional medicines for RA and other diseases, there has been increasing attention to the systematic assessment of the premodern and classical medical literature using text-mining approaches [20]. Such studies have focused on drug discovery from compounds found in the natural products used in traditional medicines [21-23]; identification of instances of long-term traditional use of natural products for certain diseases or symptoms [24-27]; the logic underlying ancient acupuncture prescriptions [28]; and investigations of continuities and differences between the classical and modern Chinese medicine approaches to certain diseases $[29,30]$. It has been proposed that long-term traditional use could be considered as a source of evidence [31], and a "whole-evidence" approach to evidencebased Chinese medicine could concludes systematic searching of the classical literature as one component [32].

This text-mining study identifies traditional formulations and their constituent natural products that have been used for conditions consistent with RA during the classical and premodern period (until 1949), compares these with the approaches recommended in contemporary guidelines for the application of herbal formulations in RA management, and examines the contemporary research into the natural products most frequently used in the traditional formulations. The study aimed to identify prospects for future clinical and experimental studies, which may lead to the development of new treatments for rheumatoid arthritis.

\section{Materials and Methods}

We searched the Encyclopaedia of Traditional Chinese Medicine (Zhong Hua Yi Dian, 5th edition) an electronic database which contains the full texts of over 1150 medical books spanning more than 2000 years [33]. This source was selected because it was the most comprehensive collection available in electronic format $[34,35]$.

The procedures for text-mining have been detailed elsewhere [36]. There is no single term in the premodern and classical Chinese literature that directly corresponds to the modern conception of RA; however, descriptions of the clinical features of RA have been included under certain traditional terms. Therefore, multiple search terms were selected based on medical nomenclatures [37, 38], clinical practice guidelines $[17,39]$, textbooks $[40,41]$, and specialist books [42-44]. Preliminary searches were conducted to determine terms that located passages of text that were suggestive of RA. After discarding unproductive terms, the following Chinese terms for classical disease names and symptoms were used to search the literature: $b i$ "arthritis" or "painful blockage", li jie "joint disease", tong feng "painful wind", he xi feng "crane's knee wind", bai hu bing "white tiger disease", ji zhua feng "chicken's claw wind", gu chui feng "drum stick wind," and wang "lameness". Each term was searched in the Zhong Hua Yi Dian (ZHYD) database, and all passages of text identified by these terms were copied to Microsoft Excel spreadsheets (by X.X, B.H.M), together with the identity of the source book and all relevant information on the disorder and intervention. A passage of text that included one or more of the search terms together with an herbal intervention for the disorder was considered a single citation. Duplications were identified and removed. Inclusion and exclusion criteria were used to identify conditions whose signs and symptoms were consistent with the features of rheumatoid arthritis. Each passage was read and allocated codes (by XX, B.H.M).

The inclusion criteria were (1) a specific herbal intervention for oral administration comprising one or more ingredients intended as a treatment for one or more of the search terms and (2) the primary condition had symptoms of joint pain and/or joint swelling, and/or limited joint function. Citations were excluded if the condition (1) had sudden or recent onset (trauma, fever, epidemic or seasonal disorder); (2) was specific to children, teenagers or females; (3) was likely due to a cerebrovascular accident (e.g., zhong feng, stroke, paralysis); or (4) was likely due to other rheumatoid disease (e.g., gout, osteoarthritis).

\section{Results and Discussion}

After removal of duplications, 3,174 citations were considered, and 548 citations of traditional formulas were included (Figure 1). The most commonly used search term was bi (258 citations) followed li jie (175 citations), tong feng (89 citations), and he xi feng $(n=14)$ but all terms were productive of citations that could have referred to RA. (TABLE SUPP 1). The citations were derived from 138 different books written from circa (ca.) $206 \mathrm{CE}$ to 1948. Most of the books were written during the Ming (1369-1644) and Qing (1645-1911) dynasties (Table 1). Prescriptions for Universal Relief (Pu Ji Fang c.1406), which is the largest book in ZHYD, provided 56 citations. The next productive book was the Compendium of Medicine (Yi Xue Gang Mu c. 1565) with 28 citations.

3.1. Example Citations. The following three citations have been translated as examples. Prescriptions for Universal Relief (volume 120) said that the formula Niu bang zi san "treats $l i$ jie caused by wind and hotness, with pain and swelling of the fingers, back and shoulders, and/or both knees." In Compendium of Medicine (volume 12) in the section on bi syndrome, it is recorded that the formula $\mathrm{He}$ xue san tong tang was used for "someone with pain and swelling in all 10 fingers that appeared one by one, and also in the knees (left then right), with attacks that can last three 


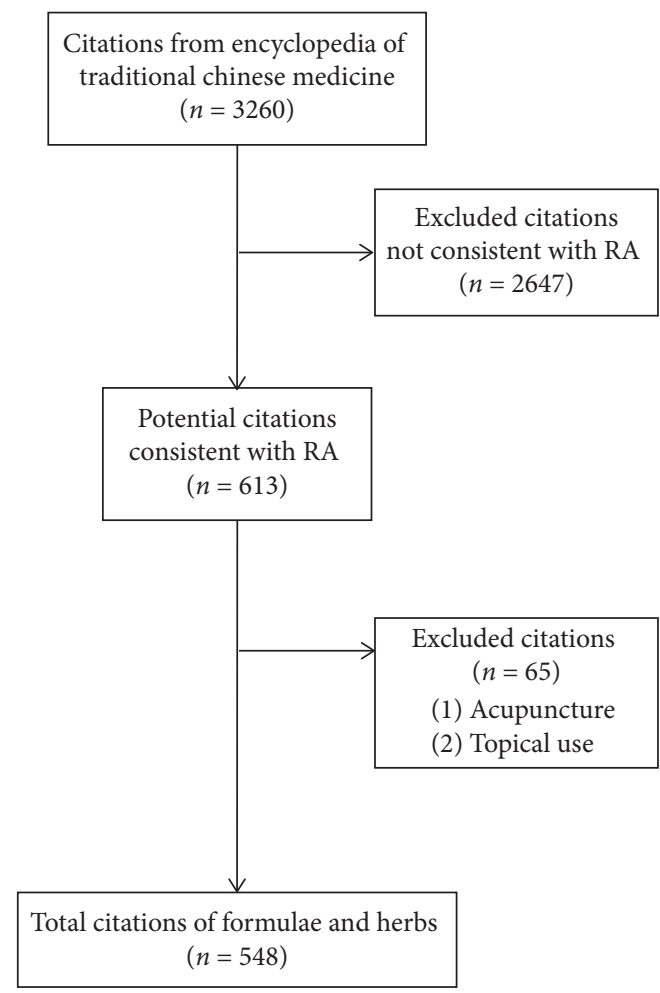

FIgURE 1: Flowchart of the search and selection process for citations of interventions for disorders consistent with rheumatoid arthritis (RA).

TABLE 1: Citations of interventions for conditions broadly consistent with rheumatoid arthritis by historical period.

\begin{tabular}{lc}
\hline Historical period (dynasty) & Frequency (percentage) $^{1}$ \\
\hline Before Tang dynasty (-617) & $1(0.20)$ \\
Tang and 5 dynasties (618-959) & $4(0.70)$ \\
Song Jin dynasties (960-1271) & $52(9.5)$ \\
Yuan dynasty (1272-1368) & $11(2.0)$ \\
Ming dynasty (1369-1644) & $245(44.7)$ \\
Qing dynasty (1645-1911) & $221(40.3)$ \\
Ming Guo period (1912-1949) & $14(2.6)$ \\
Total & $548(100)$ \\
\hline
\end{tabular}

${ }^{1}$ The dividing points between dynasties are open to interpretation, so the years have been adjusted to avoid overlap. When authors lived across two dynasties, the dynasty usually cited for the book was adopted. See May et al. [36] for how book years were determined.

to five days which are alleviated in the daytime." The book Lei Zheng Zhi Cai (ca.1839) mentioned the use of the formula $W u$ tou tang as a treatment for "li jie feng with pain in joints all over the body, just like being bitten by tiger, which is why it is also called white tiger li jie (bai hu lie jie). The symptoms are contracture and swelling of fingers, severe pain, and even limitation of function."

3.2. Frequencies of Formulas and Their Constituent Ingredients. The citations referred to 98 unnamed herbal formulas and 137 different formula names. Wu tou tang $(n=35)$ was the most common formula name, followed by
Gan cao fu zi tang $(n=28)$. These were early formulae, deriving from the book Jin Gui Yao Lue Fang Lun (ca. 206). The next most frequent were Gui zhi shao yao zhi mu tang $(n=24)$, and Si wu tang including modified versions $(n=21)$ (Table 2).

All the formulas included 5,018 ingredients (mean, 9 ingredients/formula) comprising 243 different natural products. The most frequently used were root of Glycyrrhiza uralensis Fisch (gan cao, $n=286$ ), rhizome of Zingiber officinale Rosc (jiang, $n=209$ ), root of Angelica sinensis Oliv. Diels (dang gui, $n=183$ ), root of Paeonia lactiflora Pall. (shao yao, $n=182$ ), root of Saposhnikovia divaricata Turcz. Schischk (fang feng, $n=165$ ), bark of Cinnamomum cassia Presl (gui zhi, $n=155$ ), aerial parts of Ephedra sinica Stapf (ma huang, $n=151$ ), rhizome of Atractylodes macrocephala Koidz (bai zhu, $n=147$ ), root of Ligusticum chuanxiong Hort. (chuanxiong,133), and Notopterygium incisum Ting ex H. T. Chang (qiang huo, $n=128$ ) (Table 3). From the Chinese medicine perspective, herbs are traditionally classified by flavour (wei), nature (xing), and channel tropism (gui jing) [45]. Herbs can have multiple flavours and tropisms but one nature. The flavours of the most frequent herbs were bitter $(n=18)$, pungent $(n=17)$ and/or sweet $(n=13)$. More were warm $(n=14)$ than cold $(n=7)$ in nature. The main channel tropisms were the Spleen $(n=18)$, Liver $(n=15)$, Lung $(n=13)$, Heart $(n=12)$, and Kidney $(n=10)$ channels (TABLE SUPP 3$)$.

3.3. Comparison with Contemporary Clinical Practice Guidelines. In the recent clinical practice guideline for RA [17] which is currently used by Chinese medicine doctors, 18 different herbal formulas were recommended based on the differentiation of RA into eight Chinese medicine "syndromes" or "patterns" [46]. Although a syndrome differentiation approach was not specified in the citations from the classical books, in some cases, we can infer the likely syndrome from the causative factors and/or the symptoms and signs mentioned in the citations. Of the formulas in the guidelines, eight were included in the ZHYD results: Qiang huo sheng shi tang, Wu tou tang, Gui zhi shao yao zhi mu tang, Dang gui nian tong tang, Er miao san, Huang qi gui zhi wu wu tang, Du huo ji sheng tang, and San bi tang. These related to five of the eight syndromes. Six additional formulas related to those in the guidelines were also identified (Table 4).

Although some of the more frequent classical formulae in Table 2 were absent in Table 4, the ingredients of these two lists of formulae showed considerable overlap. Of the ingredients of the formulae in the 2018 guidelines (Table 4), all except two also appeared as an ingredient in at least one of the classical formulas (allowing for differences in names). This indicates that while the formula names varied considerably, the ingredients of the modern and classical formulas tended to be drawn from a similar pool of natural products (mostly plants).

3.4. Discussion of Main Results. This text-mining study identified citations from the full texts of ancient and premodern Chinese medical books included in the ZHYD that 
TAвLE 2: Herbal formulas frequently identified in citations of treatments of conditions broadly consistent with rheumatoid arthritis.

\begin{tabular}{|c|c|c|}
\hline Formula name ${ }^{1}$ & $\underset{2}{\operatorname{Frequen}} \operatorname{cy}(n)$ & Formula ingredients ${ }^{3}$; first book in group of citations ${ }^{4}$ (year) ${ }^{5}$ \\
\hline & & Ma huang, Shao \\
\hline Gan cao fu zi tang & & 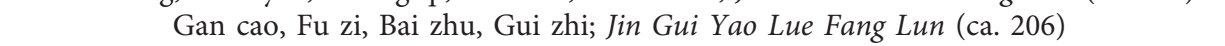 \\
\hline $\begin{array}{l}\text { Gui zhi shao yao zhi mu } \\
\text { ang }\end{array}$ & 21 & $\begin{array}{l}\text { Gui zhi, Shao yao, Gan cao, Ma huang, Sheng jiang, Bai zhu, Zhi mu, Fang feng, Fu zi; Zheng Yin } \\
\text { Mai Zhi (ca. 1641) }\end{array}$ \\
\hline Si wu tang (modified) & $16(21)$ & $\begin{array}{r}\text { Cang zhu, Huang bai, Fu zi, Gan cao, Ma huang, Tao ren, Sheng Jiang, Niu x } \\
\text { Bai zhi, Huang qin, Long dan cao; Ge Zhi Yu Lun (ca. } 13\end{array}$ \\
\hline $\operatorname{tang}$ & $12(1$ & Fang ji, Huang qi, Bai zhu, Gan cao, Sheng jiar \\
\hline $\mathrm{Vu}$ ji san & $8(12)$ & $\begin{array}{l}\text { Cang zhu, Jie geng, Zhi ke, Chen pi, Shao ya } \\
\text { Fu ling, Hou pu, Gan jiang, Ma huang, Qua }\end{array}$ \\
\hline u zi ba wu tang & 11 & , Bai zhu, Fu ling, Gui xin, Ren shen, Gan cao; Yi Fang Xuan Yao (ca. \\
\hline & & Niu bang zi, Dan dou chi, Qiang huo, Sheng di huang, Huang qi; Pu Ji Fang (ca. 1406) \\
\hline \multicolumn{3}{|c|}{$\begin{array}{l}\text { I Formulas with the same name can vary in their ingredients, and the same combination of ingredients may have different names. In these data, formulas with } \\
\text { the same core ingredients and the same name are grouped together, while those with different main ingredients are separated. Also, formulas with the same } \\
\text { ingredients but different names have been grouped together. }{ }^{2} \text { The frequency is for the name in the left column, and the number in parentheses includes } \\
\text { modified versions of the formula. }{ }^{3} \text { Formulae that include an endangered species as a primary ingredient have been excluded, when the ingredient was minor } \\
\text { and substitutable-the substitute has been recorded, when minor but not substitutable the ingredient has been excluded. For scientific names of ingredients } \\
\text { written in Pin Yin and Chinese characters for traditional medicines and book names, see glossary in supplementary file. }{ }^{4} \text { First book in group of citations; i.e., } \\
\text { the oldest book within the group of included citations, not the first book that included the formula. }{ }^{5} \text { Dates are approximate. }\end{array}$} \\
\hline
\end{tabular}

provided orally administered interventions for conditions with the clinical symptoms of joint pain and signs and symptoms that were suggestive of RA. The two most frequently cited formulas were from the earliest included book, and both these formulas are included in contemporary clinical practice guidelines. Almost 50\% $(44 \%, 8)$ of the 18 formulas in contemporary guidelines (including modified versions) were the same as formulas found in the citations from classical and premodern books, indicating considerable continuity in Chinese medicine practice for joint pain and dysfunction that were broadly consistent with the clinical symptoms of RA. However, we cannot retrospectively diagnose cases from the historical literature with any certainty so, despite our selection criteria, some of these citations may have referred to other forms of arthritis and/or joint pain due to other pathophysiology. It is important to note that the formulas and herbs were not specific to RA and could be used for other forms of arthritis, so it is a reasonable conclusion that RA was likely to have been within the scope of usage of the included herbs and formulas.

Of the 28 individual herbs that appeared frequently in the formulas from the classical and premodern literature, a little more than half (16) are listed in the contemporary Chinese pharmacopeia [47] with arthritic conditions as a primary indication. In addition, close to $100 \%$ of the ingredients of the 18 formulas in the clinical guideline were also used as ingredients in the classical formulas. This indicates there has been considerable continuity in the use of these herbs until modern times.

From the perspective of Chinese medicine, the traditional disorder " $b i$ " was mainly due to the pathogens Wind (feng), Cold (han), and Dampness (shi) causing blockages, although some types are characterized as Dampness-heat (shi re) [48, 49]. Herbs classified as bitter ( $k u)$ can dry Dampness, with bitter-warm herbs being used for Colddampness types of the disorder and bitter-cold herbs being used for Dampness-heat types [50]. There were slightly more bitter-warm/hot herbs $(n=9)$ than bitter-cold herbs $(n=7)$. Pungent herbs are used to disperse pathogens such as Wind and/or move blockages to relieve pain [50]. Most were pungent-warm $(n=15)$, which is typical of herbs in this category. Sweet herbs are mainly used for debility and chronic conditions. In addition, they are often combined with other herbs to "harmonise" (he) their effects and assist in relieving pain [50]. In terms of the tropism, the Spleen channel has associations relevant to this disorder including Dampness which shows as swelling in this condition and lack of nourishment to the muscles of the four limbs which is a feature of chronic conditions. The Liver channel is associated with disorders of the connective tissue, lack of nourishment of the tendons and joints, and loss of normal flow of $q i$ and blood leading to pain. The other channel traditionally associated with this disorder is Kidney which is associated with the condition of the bones [48, 49]. These traditional characteristics of the herbs found in the classical and premodern literature tended to reflect the viewpoint of modern textbooks. In addition, they suggest that the types of arthritis included Cold-damp and Damp-heat syndromes, although Cold-damp syndromes may have predominated. The top two channel tropisms were in accord with modern textbooks, but it is interesting to note that the Lung and Heart channels were also frequent. These are not usually associated with arthritis in traditional books. However, from a modern perspective, disorders of the pulmonary and cardiac systems are often comorbid with RA [5], and traditional formulations tend to combine ingredients to address both articular and extra-articular symptoms.

In this study, we have used frequency of appearance of a formula as a method of listing. However, frequency should not be misconstrued as an indication of effectiveness. In the case of formula ingredients, some were added to manage joint pain and swelling, while others had functional roles including 
TABLE 3: Natural products frequently used in formulas for conditions broadly consistent with rheumatoid arthritis.

\begin{tabular}{|c|c|c|c|}
\hline Scientific name (part) ${ }^{1}$ & Chinese traditional name & Frequency (n) & $\begin{array}{l}\text { In contemporary } \\
\text { pharmacopoeia }^{2}\end{array}$ \\
\hline Glycyrrhiza uralensis Fisch. (root) & Gan cao & $\begin{array}{l}286 \text { (3 sheng gan cao, } 26 \text { zhi gan } \\
\text { cao) }\end{array}$ & No \\
\hline Zingiber officinale Rosc. (rhizome) & Jiang & $\begin{array}{c}209 \text { (115 sheng jiang, } 28 \text { gan } \\
\text { jiang, } 6 \text { pao jiang) }\end{array}$ & No \\
\hline Angelica sinensis Oliv. Diels (root) & Dang gui & 183 & Yes \\
\hline Paeonia lactiflora Pall. (root) & Shao yao & $\begin{array}{c}182 \text { (28 chi shao yao, } 43 \text { bai shao } \\
\text { yao) }\end{array}$ & No \\
\hline $\begin{array}{l}\text { Saposhnikovia divaricata Turcz. Schischk } \\
\text { (root) }\end{array}$ & Fang feng & 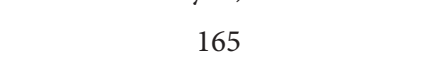 & Yes \\
\hline Cinnamomum cassia Presl. (bark) & Gui zhi & 155 & Yes \\
\hline Ephedra sinica Stapf. (herb) & Ma huang & 151 & No \\
\hline Atractylodes macrocephala Koidz. (rhizome) & Bai zhu & 147 & No \\
\hline Ligusticum chuanxiong Hort. (root) & Chuan xiong & 133 (1 xiong qiong, 2 tai qiong) & Yes \\
\hline $\begin{array}{l}\text { Notopterygium incisum Ting (root and } \\
\text { rhizome) }\end{array}$ & Qiang huo & ( & Yes \\
\hline Poria cocos Schw. Wolf (sclerotium) & Fu ling & $\begin{array}{c}127 \text { (23 chi fu ling, } 13 \text { bai fu ling, } \\
7 \text { fu shen) }\end{array}$ & No \\
\hline $\begin{array}{l}\text { Achyranthes bidentata Bl; Cyathula officinalis } \\
\text { Kuan (root) }\end{array}$ & Niu xi & 118 (9 huai niu xi, 9 chuan niu xi) & Yes \\
\hline $\begin{array}{l}\text { Aconitum carmichaelii Debx; A. kusnezoffii } \\
\text { Reichb. (root) }\end{array}$ & Wu tou & 102 (57 chuan wu, 8 cao wu) & Yes \\
\hline $\begin{array}{l}\text { Astragalus membranaceus (Fisch.) Bge. var. } \\
\text { mongholicus (Bge.) Hsiao (root) }\end{array}$ & Huang qi & 92 & Yes \\
\hline $\begin{array}{l}\text { Stephania tetrandra S. Moore; Sinomenium } \\
\text { acutum (Thunb.) Rehd. \& Wils. }{ }^{3} \text { (caulis) }\end{array}$ & Fang ji & 88 (6 han fang ji, $2 \mathrm{mu}$ fang ji) ${ }^{4}$ & Yes \\
\hline Panax ginseng C. A. Mey (root) & Ren shen & 81 & No \\
\hline Atractylodes lancea (Thunb.) DC (rhizome) & Cang zhu & 81 & Yes \\
\hline $\begin{array}{l}\text { Angelica dahurica (Fisch. ex Hoffm.) Benth. et } \\
\text { Hook. f (root) }\end{array}$ & Bai zhi & 78 & Yes \\
\hline Aconitum carmichaelii Debx (root) & Fu zi & $\begin{array}{l}72 \text { (7 sheng fu zi, } 1 \text { shu fu zi, } 57 \\
\text { pao tian xiong, } 3 \text { da fu zi) }\end{array}$ & Yes \\
\hline $\begin{array}{l}\text { Angelica pubescens Maxim. f. biserrata Shan et } \\
\text { Yuan (root) }\end{array}$ & Du huo & 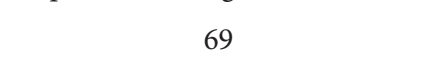 & Yes \\
\hline Scutellaria baicalensis Georgi (root) & Huang qin & 65 & No \\
\hline Citrus reticulata Blanco (peel) & Chen pi & 60 & No \\
\hline Prunus persica (L.) Batsch (seed) & Tao ren & 59 & No \\
\hline Rehmannia glutinosa Libosch. (root) & Di huang & $\begin{array}{l}56 \text { (30 sheng di huang, } 18 \text { shu di } \\
\text { huang, } 3 \text { gan di huang) }\end{array}$ & No \\
\hline Cinnamomum cassia Presl (bark) & Rou gui & 55 & Yes \\
\hline Gentiana macrophylla Pall (root) & Qin jiao & 54 & Yes \\
\hline Phellodendron amurense Rupr (bark) & Huang bai & 53 & No \\
\hline $\begin{array}{l}\text { Clematis chinensis Osbeck; C. hexapetala Pall.; } \\
\text { C. manshurica Rupr. }\end{array}$ & Wei ling xian & 45 & Yes \\
\hline
\end{tabular}

${ }^{1}$ Scientific names are based on Pharmacopoeia of the People's Republic of China 2010 and/or Great Compendium of Chinese Medicines. ${ }^{2}$ Clinical applications based on Pharmacopoeia of the People's Republic of China specified use for arthritic/rheumatic conditions. ${ }^{3}$ Also called qing feng teng. ${ }^{4}$ This herb must not be sourced from Aristolochia species.

assisting the main herbs to enhance their effects or reduce the adverse effects of some herbs, as guided by Chinese medicine theory. Therefore, the frequency of ingredients was influenced by the individualized clinical practice approach in Chinese medicine, and it does not indicate clinical effectiveness in the evidence-based healthcare context.

3.5. Modern Research into Herbs Used Frequently in the Classical Literature. Some of the classical formulas (Table 4) have received research attention in clinical trials for RA.
These include Wu tou tang [51], Wu ji san [52], Gui zhi shao yao zhi mu tang [53], Huang qi gui zhi wu wu tang [54], Dang gui nian tong tang [55], and Du huo ji sheng tang [56]. Some formulations have been investigated in experimental studies including $W u$ tou tang $[57,58]$ and Fang ji huang qi tang $[59,60]$.

From the perspective of drug discovery and development, herbs and their constituent compounds have long been sources of new molecules and structures [61-63]. To provide a brief overview of research in English literature into the single herbal ingredients, we selected the 15 herbs most 
TABLE 4: Formulas for rheumatoid arthritis in the contemporary clinical guideline and corresponding formulas in the search results.

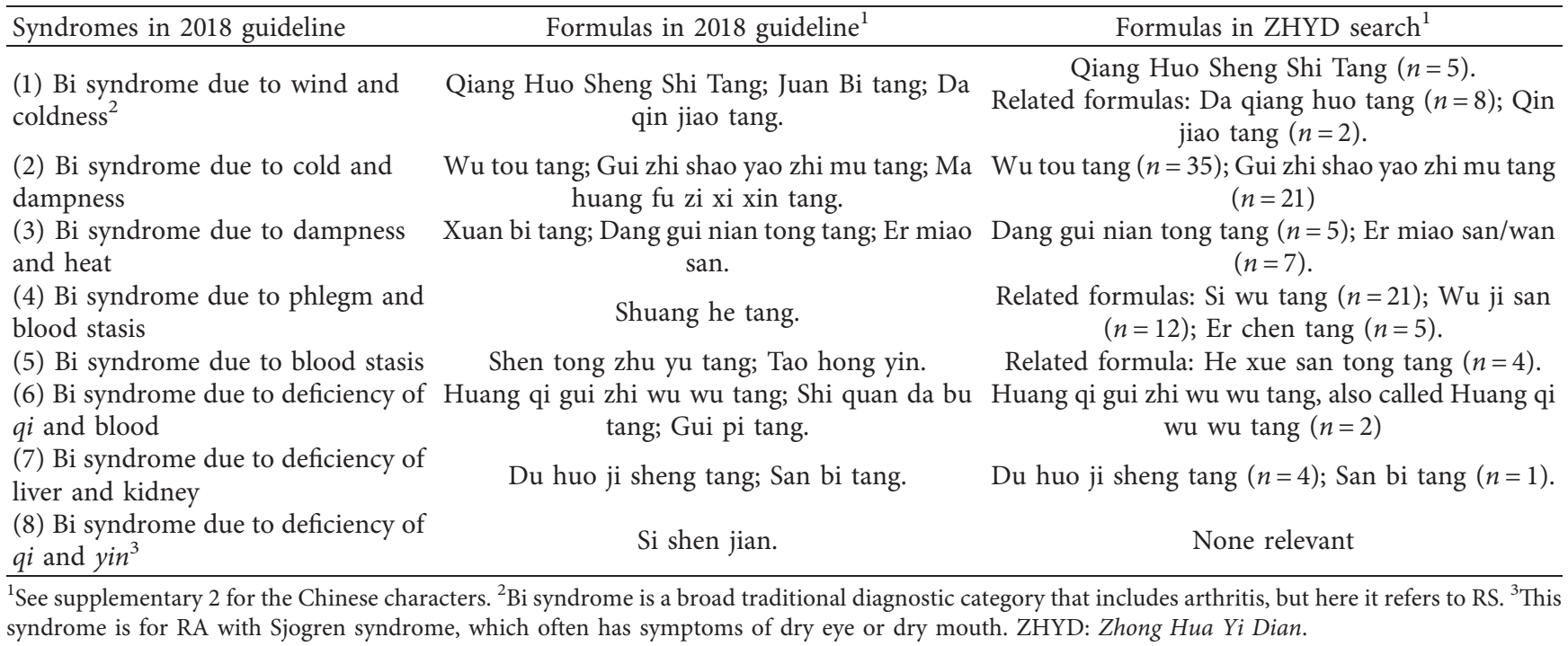

frequently included in the classical formulas (see Table 3) and summarized in-vitro, in-vivo, and human studies with a focus on the reported actions of the herbs and/or their constituent compounds in models relevant to RA (Table 5). The table has been organized according to the traditional herbal names, since this was how the list of herbs was identified, but we have grouped together items that have been processed differently, for example unprocessed licorice root (sheng gan cao) and honey-fried licorice root (zhi gan cao), and different plant parts when they have similar constituents, for example cinnamon twigs ( $g u i$ zhi) and stem bark (rou gui). In some cases, the same traditional name may apply to multiple species from the same genus; for example, the various Ephedra species are called ma huang. In other cases, the same traditional name could refer to plants from different genera. For example, niu xi is mainly sourced from Achyranthes species, but Cyathula officinalis Kuan is another source, which is now called chuan niu xi. Similarly, fang ji can derive from the stems of different vines including Stephania tetrandra S. Moore and Sinomenium acutum (Thunb.) Rehd. \& Wils (also called qing feng teng), but unfortunately it has also been sourced from toxic Aristolochia species leading to many cases of poisoning [64]. In Table 5, we have listed the main traditional names and source species for the herbs, but this is not an exhaustive list since multiple traditional names exist, the species used may have changed over time, and there can be regional variation in the preferred species. These issues all present challenges for drug discovery when traditional Chinese literature is used. However, many issues can be resolved by consulting traditional pharmacopeia from different periods, especially those with good-quality illustrations such as Shi Zheng Lei Da Guan Ben Cao (ca. 1108), good editions of Ben Cao Pin Hui Jing Yao (ca. 1505) and Ben Cao Gang Mu (ca. 1593), together with modern comprehensive works such as Zhong Hua Ben Cao [65].

With regard to research into the herbs in Table 5, two plants have already been developed into therapies for RA.
Sinomenine is derived from Sinomenium acutum (Thunb.) Rehd. \& Wils [139-140] and total glucosides of peony are from Paeonia lactiflora Pall., [141-143]. Interestingly, the plant Tripterygium wilfordii Hook F (lei gong teng) which has also been developed into therapies for RA [144-147], did not appear in any of the formulas located in this text-mining study.

Anti-inflammatory effects have been reported for each of the 15 herbs. Analgesic and antinociceptive effects have been reported for certain plants, notably the Aconitum species, Paeonia lactiflora Pall., Saposhnikovia divaricata Turcz. Schischk, Notopterygium incisum Ting, Achyranthes bidentata Bl, and Sinomenium acutum (Thunb.) Rehd. \& Wils. In reflection of the frequent clinical application of these herbs in combination with conventional medications, some studies have examined combined effects. For example, compounds from Glycyrrhiza uralensis Fisch have been reported to enhance the therapeutic effects of NSAIDs and DMARDs [68], and the compound ligustrazine derived from Ligusticum chuanxiong Hort. was reported to reduce bone cortex erosion when combined with leflunomide in a clinical study [99]. Besides the discovery of new compounds from these herbs [148], research into novel applications of multiple compounds may provide a further avenue for developing new therapeutics [149].

3.6. Limitations and Strengths of the Study. This text-mining study used ZHYD $5^{\text {th }}$ edition as the source for data- to our best knowledge the most comprehensive electronic database of classical literature in Chinese medicine. While this is a large and representative sample of premodern and classical books on Chinese medicine, it does not include every book, so there are some inevitable omissions. In addition, the terms used for searching were limited to eight, so passages of text that did not include any of these terms could not be located. It is likely that some relevant citations would not use these terms since there was no established traditional term specific to the modern diagnostic criteria of RA, so citations that simply described the clinical 
TABLE 5: Reported biological actions relevant to rheumatoid arthritis of the higher frequency herbs.

\begin{tabular}{lcc}
\hline $\begin{array}{l}\text { Traditional } \\
\text { name(s) in pin yin }\end{array}$ & Botanical source(s) & Material tested: extract/compound \\
\hline & & \\
$\begin{array}{l}\text { Gan cao, Sheng } \\
\text { gan cao, Zhi gan }\end{array}$ & $\begin{array}{c}\text { Glycyrrhiza uralensis Fisch; } \\
\text { cao }\end{array}$ & G. glabra L. (Licorice)
\end{tabular}

Jiang, Sheng

jiang, Gan jiang

Zingiber officinale Rosc (Ginger)

Extracts [69, 70], essential oils [71], shogaols, gingerols [70], 6-gingerol [72]

Dang gui

Shao yao, Bai

shao yao, Chi shao yao

Fang feng

Gui zhi, Rou gui

Cinnamomum cassia Presl

\begin{tabular}{|c|c|}
\hline Ma huang & $\begin{array}{c}\text { Ephedra sinica Stapf, other } \\
\text { Ephedra spp. }\end{array}$ \\
\hline Bai zhu & $\begin{array}{c}\text { Atractylodes macrocephala } \\
\text { Koidz }\end{array}$ \\
\hline $\begin{array}{l}\text { Chuan xiong, } \\
\text { xiong qiong }\end{array}$ & $\begin{array}{c}\text { Ligusticum chuanxiong } \\
\text { Hort. }\end{array}$ \\
\hline
\end{tabular}

Qiang huo Notopterygium incisum Ting

Fu ling, Fu shen, Chi fu ling

Poria cocos Schw. Wolf

Niu xi, Huai niu xi, Chuan niu xi

\section{(1). Achyranthes bidentata} $\mathrm{Bl}$; A. aspera L.;

(2). Cyathula officinalis Kuan

Wu tou, Chuan Aconitum carmichaelii wu, Cao wu, Fu zi Debx; A. kusnezoffii Reichb. ${ }^{3}$
Total glucosides [77-80], paeoniflorin [81], paeoniflorin- $6^{\prime}$-O-benzene sulfonate $[81,82]$

Extract [83], chromone extract [84], chromones: divaricatol, ledebouriellol and hamaudol [85], polysaccharide [86]

Extracts [88-90], cinnamic acid [90], cinnamomulactone [91]

$$
\text { Polysaccharides [92, 93] }
$$

Extract [94], atractylone [95], atractylenolide I [94], atractylenolide III [96], Sesquiterpenoids [97]; three new compounds [98]

Ligustrazine [99], Z-ligustilide, senkyunolide A [100], ligustilides [101]

Extract [102], volatile compounds [103], polyacetylenes [104], notopterol [105]

Polysaccharides [107, 108], pachymic acid, dehydrotumulosic acid [109] triterpenoids [110]

(1). Extracts [111, 112], polysaccharide [113]; (2). Extract [114]

Extracts [115-118], alkaloids [119], benzoylaconitine [120]
Reported actions relevant to RA

(i) Anti-inflammatory [66-68],

(ii) restrained angiogenesis [66],

(iii) down-regulated autoimmune reactions [67],

(iv) enhanced therapeutic effects of NSAIDs/DMARDs [68]

(i) Anti-inflammatory [69-71],

(ii) Inhibited inflammation-associated osteoclast differentiation [72]

(i) Anti-inflammatory [75],

(ii) Inhibited rheumatoid synovial fibroblast proliferation [74],

(iii) Potential interleukin 6R inhibitor [76],

(iv) Inhibited osteoclast differentiation [73]

(i) Anti-inflammatory, analgesic $[77,80]$,

(ii) Prevented bone loss/joint destruction [79, 80],

(iii) Immune regulatory [78, 81], (iv)

Inhibited synovial hypertrophy and neovascularization [80],

(v) enhanced effects of methotrexate [82]

(i) Anti-inflammatory $[83,84,86]$, (ii) Analgesic [85, 87],

(iii) Immunomodulatory [87]

(i) Anti-inflammatory [90],

(ii) Anti-arthritic, reduces joint swelling [88],

(iii) Inhibitory activity against matrix metalloproteinases [91],

(iv) Improved clinical symptoms and inflammatory markers [89]

(i) Anti-inflammatory, immunosuppressive [92, 93]

(i) Anti-inflammatory [94-98]

(i) Anti-inflammatory [100, 101],

(ii) reduced bone cortex erosion when combined with leflunomide [99]

(i) Anti-inflammatory $[103,104,106]$, (ii) Analgesic [105],

(iii) reduced swelling [102],

(iv) Anti-angiogenic [103]

(i) Anti-inflammatory [108-110], (ii) Immunomodulatory [107, 109]

(1). anti-inflammatory $[111,112]$, (i) Analgesic [111],

(ii) Suppressed osteoclastogenesis and bone resorption [113];

(2). down-regulated matrix metalloproteinase-13,

(i) Chondroprotective [114]

(i) Anti-inflammatory $[115,117,120]$, (ii) Analgesic [116, 118, 119] 
TABLE 5: Continued.

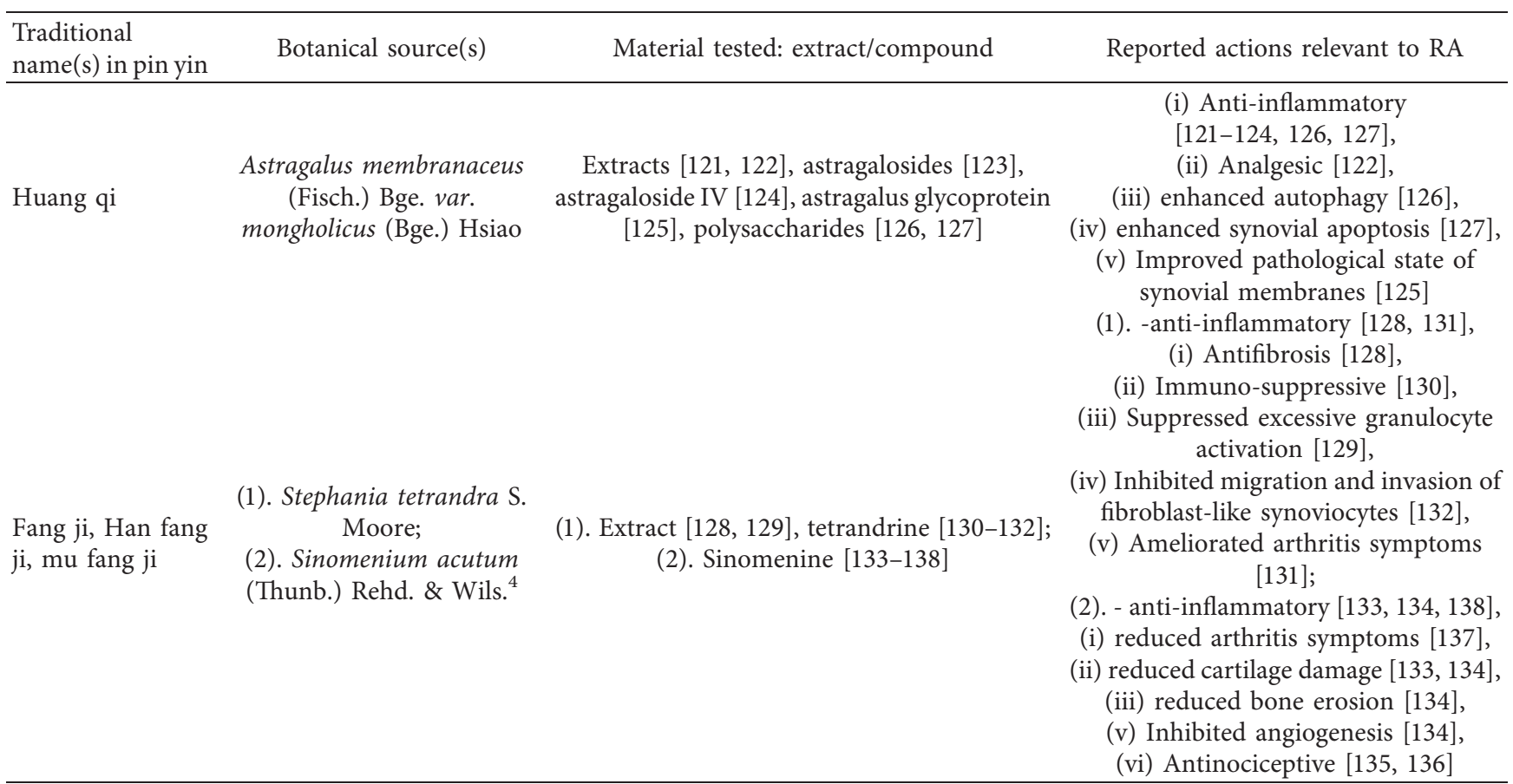

${ }^{1}$ Also called: Ledebouriella divaricata (Turcz.) Hiroe. ${ }^{2}$ Also called Ligusticum wallichii Franch. ${ }^{3}$ These species contain the toxic alkaloid aconitine. ${ }^{4}$ Also called: Cocculus orbiculatus (L.) DC. and qing feng teng.

symptoms of swollen and painful joints would have been missed. However, the search term bi has had widespread, long-term use for painful conditions, especially those of the joints, so it is likely that it would have captured most descriptions of disorders consistent with RA. Therefore, the main sources of type 2 errors (false exclusions) relate to the comprehensiveness of the sample and the limited set of search terms leading us to miss some citations of potential relevance to $\mathrm{RA}$.

On the other hand, the resultant data set was large, with 3,174 citations that required assessment (TABLE SUPP 1). Amongst these were citations unlikely to have referred to RA that were captured by the exclusion criteria. Conversely some citations mentioned typical symptoms such as multiple, painful, swollen, and finger joints. However, our modern conception of RA was not shared by doctors in premodern times, so they did not always provide the details we would like. In many citations, there was joint pain but not enough additional detail to distinguish the likely cause. Hence, these were considered as "possible" RA. This is the major source of type 1 errors (false inclusions) in this analysis, since it is likely that such citations could have referred to osteoarthritis or other chronic joint disorders. In the case of the most productive search term, bi, only 258 out of 2,147 citations (12\%) were considered "possible RA". This reflects the broad scope of meaning of this traditional term and our requirement that joint pain be specified. In contrast, the term $l i$ jie yielded a $40 \%$ inclusion rate since it was more specific to painful joints. In the case of the term he xi feng only $9.3 \%$ of citations were included since this condition mainly presents with swelling of the knee consistent with osteoarthritis of the knee. Therefore, our procedures eliminated a considerable proportion of the original data set as not consistent with RA or too unclear for inclusion.

Applying more stringent criteria overall would have further reduced the total number of included citations, at the expense of increasing the number of type 2 errors. We did not take this approach since were interested in identifying candidate formulas for clinical studies and herbs for drug discovery. We were also aware that the same herbal formulas could be used for a range of arthritic disorders, so we did not want to exclude formulas that would have been used for RA plus other disorders. As the results of the experimental studies demonstrate, this approach was productive in identifying herbs that have received varying degrees of research attention of relevance to RA, since all the herbs in Table 5 have histories of use for painful joint disorders and have shown biological activities relevant to RA management in recent studies. Moreover, the identified herbs have all been used in humans, so any toxicity issues are likely to have been identified. Nevertheless, the pathway from identifying candidates to the development of new interventions still requires extensive preclinical and clinical research [150].

\section{Conclusions}

This text-mining study of a large sample of the premodern and classical Chinese medicine literature identified herbal interventions for joint disorders associated with possible RA. When the results for the formulas were compared with the recommendations in the current clinical practice guidelines for the treatment of RA using Chinese herbal medicine, there was considerable overlap, suggesting considerable continuity between historical and modern clinical practice. At the 
level of the individual ingredient, all the top 15 herbs frequently used in the classical formulas have also been reported to demonstrate anti-inflammatory activity in experimental studies and some have already received considerable research attention as candidates for RA drug discovery. These results suggest this text-mining approach was productive in identifying potential natural products for further research.

\section{Data Availability}

The database used in this study is commercially available. The datasets used for this study are available from the authors upon reasonable request.

\section{Conflicts of Interest}

The authors declare that the research was conducted in the absence of any commercial or financial relationships that could be construed as a potential conflicts of interest.

\section{Authors' Contributions}

Searches, data extraction, and data analyses were conducted by Dr Xuan Xia and Dr Brian H May. The draft manuscript was drafted by Dr Xuan Xia and Dr Brian H May with critical input from all other authors during the revisions the draft manuscripts. Prof. Qingchun Huang, Dist. Prof. Charlie C. Xue, Assoc. Prof. Anthony L Zhang, Prof. Xinfeng Guo and Prof. Chuanjian Lu provided expert contributions to the conception and design of the project, the methodology, and data interpretation.

\section{Acknowledgments}

The authors acknowledge the funding support provided by the National Key Research and Development Project (nos. 2018YFC1705200 and 2018YFC1705203) and the ChinaAustralia International Research Centre for Chinese Medicine (CAIRCCM), a joint initiative of RMIT University, Australia, and Guangdong Provincial Academy of Chinese Medical Sciences, China, and the Foundation for Chinese Medicine and Technology Research of Guangdong Provincial Hospital of Chinese Medicine (2017KT1820, 2016KT1571).

\section{Supplementary Materials}

TABLE SUPP 1: frequency of citations for formula interventions identified by the search terms at different stages in the selection procedure. SUPP 2: glossary of Pin yin, Chinese, and scientific names for traditional medicines, books, formulas, and other terms cited in the text and tables. TABLE SUPP 3: traditional properties of the most frequent herbs: channel tropism, flavour, nature. (Supplementary Materials)

\section{References}

[1] D. Aletaha, T. Neogi, A. J. Silman et al., "Rheumatoid arthritis classification criteria: an American college of
rheumatology/European league against rheumatism collaborative initiative," Arthritis \& Rheumatism, vol. 62, no. 9, pp. 2569-2581, 2010.

[2] D. L. Scott, B. L. Coulton, D. P. M. Symmons, and A. J. Popert, "Long-term outcome of treating rheumatoid arthritis: results after 20 years," The Lancet, vol. 329, no. 8542, pp. 1108-1111, 1987.

[3] D. M. Mitchell, P. W. Spitz, D. Y. Young, D. A. Bloch, D. J. Mcshane, and J. F. Fries, "Survival, prognosis, and causes of death in rheumatoid arthritis," Arthritis \& Rheumatism, vol. 29, no. 6, pp. 706-714, 1986.

[4] M. Cross, E. Smith, D. Hoy et al., "The global burden of rheumatoid arthritis: estimates from the global burden of disease 2010 study," Annals of the Rheumatic Diseases, vol. 73, no. 7, pp. 1316-1322, 2014.

[5] J. A. Sparks, "Rheumatoid arthritis," Annals of Internal Medicine, vol. 170, no. 1, pp. ITC1-ITC16, 2019.

[6] J. W. J. Bijlsma and M. E. Weinblatt, "Optimal use of methotrexate: the advantages of tight control," Annals of the Rheumatic Diseases, vol. 66, no. 11, pp. 1409-1410, 2007.

[7] K. Visser and D. van der Heijde, "Optimal dosage and route of administration of methotrexate in rheumatoid arthritis: a systematic review of the literature," Annals of the Rheumatic Diseases, vol. 68, no. 7, pp. 1094-1099, 2009.

[8] J. S. Smolen, D. Aletaha, M. Koeller, M. H. Weisman, and P. Emery, "New therapies for treatment of rheumatoid arthritis," The Lancet, vol. 370, no. 9602, pp. 1861-1874, 2007.

[9] T. Doan and E. Massarotti, "Rheumatoid arthritis: an overview of new and emerging therapies," The Journal of Clinical Pharmacology, vol. 45, no. 7, pp. 751-762, 2005.

[10] C. Zhang, M. Jiang, X.-J. He, and A.-P. Lu, "Clinical trials of integrative medicine for rheumatoid arthritis: issues and recommendations," Chinese Journal of Integrative Medicine, vol. 21, no. 6, pp. 403-407, 2015.

[11] J. Weeks, "Chinese TCM renaissance and the global movement for integrative health and medicine," The Journal of Alternative and Complementary Medicine, vol. 23, no. 2, pp. 79-81, 2017.

[12] C. Zhang, M. Jiang, and A.-P. Lü, "Evidence-based Chinese medicine for rheumatoid arthritis," Journal of Traditional Chinese Medicine, vol. 31, no. 2, pp. 152-157, 2011.

[13] P. C. Chou and H. Y. Chu, "Clinical efficacy of acupuncture on rheumatoid arthritis and associated mechanisms: a systemic review," Evidence-Based Complementary and Alternative Medicine, vol. 2018, Article ID 8596918, 21 pages, 2018.

[14] S. Lü, Q. Wang, G. Li, S. Sun, Y. Guo, and H. Kuang, "The treatment of rheumatoid arthritis using Chinese medicinal plants: from pharmacology to potential molecular mechanisms," Journal of Ethnopharmacology, vol. 176, pp. 177-206, 2015.

[15] K. D. Moudgil and B. M. Berman, "Traditional Chinese medicine: potential for clinical treatment of rheumatoid arthritis," Expert Review of Clinical Immunology, vol. 10, no. 7, pp. 819-822, 2014.

[16] M. Cameron, J. J. Gagnier, C. V. Little, T. J. Parsons, A. BlÃ $1 / 4 \mathrm{mle}$, and S. Chrubasik, "Evidence of effectiveness of herbal medicinal products in the treatment of arthritis," Phytotherapy Research, vol. 23, no. 12, pp. 1647-1662, 2009.

[17] Q. Jiang, H. L. Wang, X. Gong, and C. G. Luo, "Guideline for diagnosis and treatment of rheumatoid arthritis based on TCM syndromes," Journal of Traditional Chinese Medicine, vol. 59, no. 20, pp. 1794-1800, 2018.

[18] R.-Y. Huang, H.-D. Pan, J.-Q. Wu et al., "Comparison of combination therapy with methotrexate and sinomenine or 
leflunomide for active rheumatoid arthritis: a randomized controlled clinical trial," Phytomedicine, vol. 57, pp. 403-410, 2019.

[19] Y. Z. Zhou, L. D. Zhao, H. Chen et al., "Comparison of the impact of Tripterygium wilfordii Hook F and Methotrexate treatment on radiological progression in active rheumatoid arthritis: 2-year follow up of a randomized, non-blinded, controlled study," Arthritis Research \& Therapy, vol. 20, no. 1, p. 70, 2018.

[20] E. Buenz, D. Schnepple, B. Bauer, P. Elkin, J. Riddle, and T. Motley, "Techniques: bioprospecting historical herbal texts by hunting for new leads in old tomes," Trends in Pharmacological Sciences, vol. 25, no. 9, pp. 494-498, 2004.

[21] M. Adams, C. Berset, M. Kessler, and M. Hamburger, "Medicinal herbs for the treatment of rheumatic disorders-a survey of European herbals from the 16th and 17th century," Journal of Ethnopharmacology, vol. 121, no. 3, pp. 343-359, 2009.

[22] E. J. Buenz, B. A. Bauer, H. E. Johnson et al., "Searching historical herbal texts for potential new drugs," British Medical Journal, vol. 333, no. 7582, pp. 1314-1315, 2006.

[23] F. Watkins, B. Pendry, O. Corcoran, and A. Sanchez-Medina, "Anglo-Saxon pharmacopoeia revisited: a potential treasure in drug discovery," Drug Discovery Today, vol. 16, no. 23-24, pp. 1069-1075, 2011.

[24] J. L. Shergis, L. Wu, B. H. May et al., "Natural products for chronic cough," Chronic Respiratory Disease, vol. 12, no. 3, pp. 204-211, 2015.

[25] L. Zhang, Y. Li, X. F. Guo et al., "Text mining of the classical medical literature for medicines that show potential in diabetic nephropathy," Evidence-Based Complementary and Alternative Medicine, vol. 2014, Article ID 189125, 12 pages, 2014.

[26] H. W. Bae, S. Y. Lee, S. J. Kim, H. K. Shin, B. T. Choi, and J. U. Baek, "Selecting effective herbal medicines for attentiondeficit/hyperactivity disorder via text mining of donguibogam," Evidence-Based Complementary and Alternative Medicine, vol. 2019, Article ID 1798364, 9 pages, 2019.

[27] M. J. Choi, B. T. Choi, H. K. Shin, B. C. Shin, Y. K. Han, and J. U. Baek, "Establishment of a comprehensive list of candidate antiaging medicinal herb used in Korean medicine by text mining of the classical Korean medical literature, "dongeuibogam," and preliminary evaluation of the antiaging effects of these herbs," Evidence-Based Complementary and Alternative Medicine, vol. 2015, Article ID 873185, 29 pages, 2015.

[28] J. Z. Chen, Q. Jiang, Z. Liu, and X. Y. Zhou, "Acupoint research on thirst symptom of primary Sjogren's syndrome (pSS) based on ancient documents," Journal of Clinical Acupuncture and Moxibustion, vol. 32, no. 12, pp. 74-77, 2017.

[29] C. S. Zhang, B. May, Y. Yan et al., "Terms referring to psoriasis vulgaris in the classical Chinese medicine literature: a systematic analysis," Complementary Therapies in Medicine, vol. 25, pp. 55-60, 2016.

[30] B. H. May, M. Feng, I. W. Zhou et al., "Memory impairment, dementia, and alzheimer's disease in classical and contemporary traditional Chinese medicine," The Journal of Alternative and Complementary Medicine, vol. 22, no. 9, pp. 695-705, 2016.

[31] A. Helmstädter and C. Staiger, "Traditional use of medicinal agents: a valid source of evidence," Drug Discovery Today, vol. 19, no. 1, pp. 4-7, 2014.
[32] C. C. Xue and Y. Lyu, "Accelerating the comprehensive and systematic evaluation of clinical evidence for Chinese medicine using a whole-evidence approach," Global Health Journal, vol. 3, no. 2, pp. 33-36, 2019.

[33] R. Hu, Z. Hua, and Y. Dian, Encyclopaedia of Traditional Chinese Medicine, Changsha: Hunan Electronic and AudioVisual, Publishing House, Changsha, China, 5th edition, 2014.

[34] B. H. May, C. Lu, and C. C. L. Xue, "Collections of traditional Chinese medical literature as resources for systematic searches," The Journal of Alternative and Complementary Medicine, vol. 18, no. 12, pp. 1101-1107, 2012.

[35] B. H. May, Y. Lu, C. Lu, A. L. Zhang, S. Chang, and C. C. L. Xue, "Systematic assessment of the representativeness of published collections of the traditional literature on Chinese medicine," The Journal of Alternative and Complementary Medicine, vol. 19, no. 5, pp. 403-409, 2013.

[36] B. H. May, A. Zhang, Y. Lu, C. Lu, and C. C. L. Xue, "The systematic assessment of traditional evidence from the premodern Chinese medical literature: a text-mining approach," The Journal of Alternative and Complementary Medicine, vol. 20, no. 12, pp. 937-942, 2014.

[37] Y. L. Zhao, Z. F. Zhang, G. Jia, and B. Zhun, Zhong Yi Lin Chuang Zhen Liao Shu Yu-Zheng Zhi Yao Lan, Hu Nan Ke Xue Ji Shu Chu Ban She, Changsha, China, 1999.

[38] Z. J. Jianduju, Zhong Yi Bing Zheng Fen Lei Yu Dai Ma 'Standard Nomenclature for Disease Names and Syndromes in Chinese Medicine, Zhong Guo biao Zhun Chu Ban She, Beijing, China, 1996.

[39] China Academy of Chinese Medical Sciences, Zhong Yi Xun Zheng Lin Chuang Shi Jian Zhi Nan, China Press of Traditional Chinese Medicine, Beijing, China, 2011.

[40] S. Y. Yu, Integrated Traditional Chinese and Western Medicine, China Science Press, Beijing, China, 2nd edition, 2008.

[41] Z. Y. Zhou, Chinese Internal Medicine, China Press of Traditional Chinese Medicine, Beijing, China, 2nd edition, 2007.

[42] C. D. Wang, Zhong Yi Lin Chuang Zhen Liao Zhi Nan Shi YiFeng Shi Bing Fen Ce, China Press of Traditional Chinese Medicine, Beijing, China, 2015.

[43] Y. Shen, Summary of Diagnosis and Treatment of Rheumatoid Diseases in Traditional Chinese and Western Medicine (Feng Shi Bing Zhong Xi Yi Zhen Liao Gai Yao), Military Science Publishing House, Beijing, China, 2006.

[44] Z. Z. Lu and S. D. Jiao, Practical Chinese Rheumatology (Shi Yong Zhong Yi Feng Shi Bing Xue), People's Medical Publishing House, Beijing, China, 1996.

[45] P. Liu, S. Liu, G. Chen, and P. Wang, "Understanding channel tropism in traditional Chinese medicine in the context of systems biology," Frontiers of Medicine, vol. 7, no. 3, pp. 277-279, 2013.

[46] C. Lu, Q. Zha, A. Chang, Y. He, and A. Lu, "Pattern differentiation in Traditional Chinese Medicine can help define specific indications for biomedical therapy in the treatment of rheumatoid arthritis," The Journal of Alternative and Complementary Medicine, vol. 15, no. 9, pp. 1021-1025, 2009.

[47] Chinese Pharmacopoeia Commission, Pharmacopoeia of the People's Republic of China (Zhong Hua Ren Min Gong He Guo Yao Dian), China Medical Science Press, Beijing, China, 2015.

[48] Y. Q. Lou, Rheumatology in Chinese Medicine (Zhong Yi Feng Shi Bing Xue), People's Medical Publishing House, Beijing, China, 2010. 
[49] Q. F. Wu and Z. Z. Ye, Rheumatic Diseases-the Traditional Chinese Medicine Approach to Treatment (Feng Shi Bing Zhong Yi Te Se Zhi Liao), Liaoning science and technology publishing house, Shenyang, China, 2002.

[50] Z. S. Huang, Chinese Herbal Medicines (Zhong Yao Xue), People's medical publishing house, Beijing, Chnina, 2002.

[51] Y. Wang and S. H. Tu, "Clinical study on modified Wutou decoction in treatment of rheumatoid arthritis," Acta Chinese Medicine, vol. 9, no. 32, pp. 1716-1719, 2017.

[52] D. K. Zhang, "Clinical observation of Wu Ji san in treating active rheumatoid arthritis," Journal of New Chinese Medicine, vol. 42, no. 10, pp. 24-25, 2010.

[53] J. W. Daily, T. Zhang, S. Cao, and S. Park, "Efficacy and safety of GuiZhi-ShaoYao-ZhiMu decoction for treating rheumatoid arthritis: a systematic review and meta-analysis of randomized clinical trials," The Journal of Alternative and Complementary Medicine, vol. 23, no. 10, pp. 756-770, 2017.

[54] Q. W. Yang, X. L. Li, Q. C. Huang et al., "Clinical observation of curative effects of Huangqi Guizhi Wuwu Decoction in the treatment of rheumatoid arthritis," World Chinese Medicine, vol. 13, no. 4, pp. 861-864, 2018.

[55] L. Ge and Z. M. Shi, "Clinical trial treating rheumatoid arthritis comparing Dang Gui Nian Tong Tang combined with methotrexate," Chinese Medicine and Pharmacology, vol. 45, no. 2, pp. 84-86, 2017.

[56] X. Qian, X. Chen, G. Wei, Y. K. Guo, and Z. L. Sun, "Clinical effect of Duhuo Jisheng Tang combined with meloxicam in treatment of rheumatoid arthritis," Chinese Journal of Experimental Traditional Medicine Formulae, vol. 22, no. 7, pp. 173-176, 2016.

[57] Y. F. Liu, C. Y. Wen, Z. Chen et al., "Effects of wutou decoction on DNA methylation and histone modifications in rats with collagen-induced arthritis," Evidence-Based Complementary and Alternative Medicine, vol. 2016, Article ID 5836879, 9 pages, 2016.

[58] Y. Q. Zhang, D. H. Wang, S. F. Tan, H. Y. Xu, C. F. Liu, and N. Lin, "A systems biology-based investigation into the pharmacological mechanisms of $\mathrm{Wu}$ tou tang acting on rheumatoid arthritis by integrating network analysis," Evidence-Based Complementary and Alternative Medicine, vol. 2013, Article ID 548498, 12 pages, 2013.

[59] X. Zhang, Z. Wu, Y. Liu et al., "Boi-ogi-to (TJ-20), a kampo formula, suppresses the inflammatory bone destruction and the expression of cytokines in the synovia of ankle joints of adjuvant arthritic rats," Evidence-Based Complementary and Alternative Medicine, vol. 2017, Article ID 3679295, 10 pages, 2017.

[60] Y. C. Lin, C. W. Chang, and C. R. Wu, "Anti-nociceptive, anti-inflammatory and toxicological evaluation of Fang-JiHuang-Qi-Tang in rodents," BMC Complementary and Alternative Medicine, vol. 15, no. 1, p. 10, 2015.

[61] D. J. Newman, G. M. Cragg, and K. M. Snader, "Natural products as sources of new drugs over the period 1981-2002," Journal of Natural Products, vol. 66, no. 7, pp. 1022-1037, 2003.

[62] D. J. Newman and G. M. Cragg, "Natural products as sources of new drugs from 1981 to 2014," Journal of Natural Products, vol. 79, no. 3, pp. 629-661, 2016.

[63] G. M. Cragg and D. J. Newman, "Natural products: a continuing source of novel drug leads," Biochimica et Biophysica Acta (BBA)-General Subjects, vol. 1830, no. 6, pp. 3670-3695, 2013.

[64] T. P. Cheung, C. Xue, K. Leung, K. Chan, and C. G. Li, "Aristolochic acids detected in some raw Chinese medicinal herbs and manufactured herbal products: a consequence of inappropriate nomenclature and imprecise labelling?" Clinical Toxicology, vol. 44, no. 4, pp. 371-378, 2006.

[65] State of Administration of Traditional Chinese Medicine, Chinese Materia Medica (Zhong Hua Ben Cao), Shanghai Science and Technology Publisher, Shanghai, China, 1999.

[66] K.-F. Zhai, H. Duan, C.-Y. Cui et al., "Liquiritin from Glycyrrhiza uralensis attenuating rheumatoid arthritis via reducing inflammation, suppressing angiogenesis, and inhibiting MAPK signaling pathway," Journal of Agricultural and Food Chemistry, vol. 67, no. 10, pp. 2856-2864, 2019.

[67] Y. Fu, H. Zhou, S. Wang, and Q. Wei, "Glycyrol suppresses collagen-induced arthritis by regulating autoimmune and inflammatory responses," PLoS One, vol. 9, no. 7, Article ID e98137, 2014.

[68] Q. C. Huang, M. J. Wang, X. M. Chen et al., "Can active components of licorice, glycyrrhizin and glycyrrhetinic acid, lick rheumatoid arthritis?" Oncotarget, vol. 7, no. 2, pp. 1193-1202, 2016.

[69] J. L. Funk, J. B. Frye, J. N. Oyarzo, and B. N. Timmermann, "Comparative effects of two gingerol-containing Zingiber officinale extracts on experimental rheumatoid arthritis," Journal of Natural Products, vol. 72, no. 3, pp. 403-407, 2009.

[70] A. Al-Nahain, R. Jahan, and M. Rahmatullah, "Zingiber officinale: a potential plant against rheumatoid arthritis," Arthritis,vol. 2014 Article ID 159089, 8 pages, 2014.

[71] J. L. Funk, J. B. Frye, J. N. Oyarzo, J. Chen, H. Zhang, and B. N. Timmermann, "Anti-inflammatory effects of the essential oils of ginger (Zingiber officinale roscoe) in experimental rheumatoid arthritis," PharmaNutrition, vol. 4, no. 3, pp. 123-131, 2016.

[72] Y.-H. Hwang, T. Kim, R. Kim, and H. Ha, "The natural product 6-gingerol inhibits inflammation-associated osteoclast differentiation via reduction of prostaglandin E2 levels," International Journal of Molecular Sciences, vol. 19, no. 7, p. 2068, 2018.

[73] L. Kong, Q. Zhao, X. Wang, J. Zhu, D. Hao, and C. Yang, "Angelica sinensis extract inhibits RANKL-mediated osteoclastogenesis by down-regulated the expression of NFATc1 in mouse bone marrow cells," BMC Complementary and Alternative Medicine, vol. 14, no. 1, p. 481, 2014.

[74] W.-S. Lee, J.-H. Lim, M.-S. Sung, E.-G. Lee, Y.-J. Oh, and W.-H. Yoo, "Ethyl acetate fraction from Angelica sinensis inhibits IL- $1 \beta$-induced rheumatoid synovial fibroblast proliferation and COX-2, PGE2, and MMPs production," Biological Research, vol. 47, no. 1, p. 41, 2014.

[75] C. L. H. Yang, T. C. T. Or, M. H. K. Ho, and A. S. Y. Lau, "Scientific basis of botanical medicine as alternative remedies for rheumatoid arthritis," Clinical Reviews in Allergy \& Immunology, vol. 44, no. 3, pp. 284-300, 2013.

[76] W. Y. Lee, H. Y. Chen, K. C. Chen, and C. Y. Chen, "Treatment of rheumatoid arthritis with traditional Chinese medicine," BioMed Research International, vol. 2014, Article ID 528018, 11 pages, 2014.

[77] D. Y. He and S. M. Dai, "Anti-inflammatory and immunomodulatory effects of Paeonia lactiflora pall., a traditional Chinese herbal medicine," Front Pharmacol, vol. 2, no. 10, 2011.

[78] J. Lin, L. Xiao, G. Ouyang et al., "Total glucosides of paeony inhibits Th1/Th17 cells via decreasing dendritic cells activation in rheumatoid arthritis," Cellular Immunology, vol. 280, no. 2, pp. 156-163, 2012.

[79] C. C. Wei, F. T. You, L. Y. Mei, S. Jian, and C. Y. Qiang, "Total glucosides of paeony prevents juxta-articular bone loss 
in experimental arthritis," BMC Complementary and Alternative Medicine, vol. 13, no. 1, p. 186, 2013.

[80] W. Zhang and S.-M. Dai, "Mechanisms involved in the therapeutic effects of Paeonia lactiflora Pallas in rheumatoid arthritis," International Immunopharmacology, vol. 14, no. 1, pp. 27-31, 2012.

[81] J. Tu, Y. Guo, W. Hong et al., "The regulatory effects of paeoniflorin and its derivative paeoniflorin-6'-O-benzene sulfonate CP-25 on inflammation and immune diseases," Frontiers in Pharmacology, vol. 10, p. 57, 2019.

[82] J. Asenso, J. Yu, F. Xiao et al., "Methotrexate improves the anti-arthritic effects of Paeoniflorin-'-O-benzene sulfonate by enhancing its pharmacokinetic properties in adjuvantinduced arthritis rats," Biomedicine \& Pharmacotherapy, vol. 112, Article ID 108644, 2019.

[83] J. M. Chun, H. S. Kim, A. Y. Lee, S. H. Kim, and H. K. Kim, "Anti-inflammatory and antiosteoarthritis effects of Saposhnikovia divaricata ethanol extract: in vitro and in vivo studies," Evidence-Based Complementary and Alternative Medicine, vol. 2016 Article ID 1984238, 8 pages, 2016.

[84] X. Kong, C. Liu, C. Zhang et al., "The suppressive effects of Saposhnikovia divaricata (Fangfeng) chromone extract on rheumatoid arthritis via inhibition of nuclear factor- $\kappa \mathrm{B}$ and mitogen activated proteinkinases activation on collageninduced arthritis model," Journal of Ethnopharmacology, vol. 148, no. 3, pp. 842-850, 2013.

[85] E. Okuyama, T. Hasegawa, T. Matsushita, H. Fujimoto, M. Ishibashi, and M. Yamazaki, "Analgesic components of saposhnikovia root (Saposhnikovia divaricata)," Chemical \& Pharmaceutical Bulletin, vol. 49, no. 2, pp. 154-160, 2001.

[86] B. Ci, W. Wang, and Y. Ni, "Inhibitory effect of Saposhnikovia divaricate polysaccharide on fibroblast-like synoviocytes from rheumatoid arthritis rat in vitro," Pakistan journal of pharmaceutical sciences, vol. 31, no. 6, pp. 2791-2798, 2018.

[87] J. Kreiner, E. Pang, G. B. Lenon, and A. W. H. Yang, "Saposhnikoviae divaricata: a phytochemical, pharmacological, and pharmacokinetic review," Chinese Journal of Natural Medicines, vol. 15, no. 4, pp. 255-264, 2017.

[88] H. Sharma, P. Chauhan, and S. Singh, "Evaluation of the anti-arthritic activity of Cinnamomum cassia bark extract in experimental models," Integrative Medicine Research, vol. 7, no. 4, pp. 366-373, 2018.

[89] F. Shishehbor, M. Rezaeyan Safar, E. Rajaei, and M. H. Haghighizadeh, "Cinnamon consumption improves clinical symptoms and inflammatory markers in women with rheumatoid arthritis," Journal of the American College of Nutrition, vol. 37, no. 8, pp. 685-690, 2018.

[90] E. Pontiki and D. Hadjipavlou-Litina, "Multi-target cinnamic acids for oxidative stress and inflammation: design, synthesis, biological evaluation and modeling studies," Molecules, vol. 24, no. 1, p. 12, 2018.

[91] G. J. Kim, J. Y. Lee, H. G. Choi et al., "Cinnamomulactone, a new butyrolactone from the twigs of Cinnamomum cassia and its inhibitory activity of matrix metalloproteinases," Archives of Pharmacal Research, vol. 40, no. 3, pp. 304-310, 2017.

[92] H. Kuang, Y. Xia, J. Liang, B. Yang, Q. Wang, and X. Wang, "Structural characteristics of a hyperbranched acidic polysaccharide from the stems of Ephedra sinica and its effect on T-cell subsets and their cytokines in DTH mice," Carbohydrate Polymers, vol. 86, no. 4, pp. 1705-1711, 2011.

[93] Q. Wang, Z. Shu, N. Xing et al., "A pure polysaccharide from Ephedra sinica treating on arthritis and inhibiting cytokines expression," International Journal of Biological Macromolecules, vol. 86, pp. 177-188, 2016.

[94] C.-Q. Li, L.-C. He, H.-Y. Dong, and J.-Q. Jin, "Screening for the anti-inflammatory activity of fractions and compounds from Atractylodes macrocephala koidz," Journal of Ethnopharmacology, vol. 114, no. 2, pp. 212-217, 2007.

[95] S. Gu, L. Li, H. Huang, B. Wang, and T. Zhang, "Antitumor, antiviral, and anti-inflammatory efficacy of essential oils from Atractylodes macrocephala koidz. Produced with different processing methods," Molecules, vol. 24, no. 16, p. 2956, 2019.

[96] G.-Q. Ji, R.-Q. Chen, and L. Wang, "Anti-inflammatory activity of atractylenolide III through inhibition of nuclear factor- $\kappa \mathrm{B}$ and mitogen-activated protein kinase pathways in mouse macrophages," Immunopharmacology and Immunotoxicology, vol. 38, no. 2, pp. 98-102, 2016.

[97] L. S. Hoang, M. H. Tran, J.-S. Lee, Q. M. T. Ngo, M. H. Woo, and B. S. Min, "Inflammatory inhibitory activity of sesquiterpenoids from Atractylodes macrocephala rhizomes," Chemical and Pharmaceutical Bulletin, vol. 64, no. 5, pp. 507-511, 2016.

[98] D. Jeong, G. Z. Dong, H. J. Lee, and J. H. Ryu, "Anti-inflammatory compounds from Atractylodes macrocephala," Molecules, vol. 24, no. 10, p. 1859, 2019.

[99] C. Zhang, D. G. Guan, M. Jiang et al., "Efficacy of leflunomide combined with ligustrazine in the treatment of rheumatoid arthritis: prediction with network pharmacology and validation in a clinical trial," Chinese Medicine, vol. 14, no. $1,2019$.

[100] L. Liu, Z.-Q. Ning, S. Shan et al., "Phthalide lactones fromLigusticum chuanxiongInhibit lipopolysaccharide-induced TNF- $\alpha$ production and TNF- $\alpha$-mediated NF- $\kappa$ B activation," Planta Medica, vol. 71, no. 9, pp. 808-813, 2005.

[101] J. Huang, X.-Q. Lu, C. Zhang et al., "Anti-inflammatory ligustilides from Ligusticum chuanxiong Hort," Fitoterapia, vol. 91, pp. 21-27, 2013.

[102] Y. Wang, Z. Chen, C. Liu, X. Lu, C. Yang, and S. Qiu, "Distributive differences of P2Xs between the forelimb and hind limb of adjuvant arthritis rats and intervention by Notopterygh rhizoma et radix," Pharmaceutical Biology, vol. 57, no. 1, pp. 81-88, 2019.

[103] J.-P. Bi, P. Li, X.-X. Xu, T. Wang, and F. Li, “Anti-rheumatoid arthritic effect of volatile components in notopterygium incisum in rats via anti-inflammatory and antiangiogenic activities," Chinese Journal of Natural Medicines, vol. 16, no. 12, pp. 926-935, 2018.

[104] M. Blunder, X. Liu, O. Kunert et al., "Polyacetylenes from radix et rhizoma notopterygii incisi with an inhibitory effect on nitric oxide production in vitro," Planta Medica, vol. 80, no. 5, pp. 415-418, 2014.

[105] E. Okuyama, S. Nishimura, S. Ohmori, Y. Ozaki, M. Satake, and M. Yamazaki, "Analgesic component of notopterygium incisum ting," Chemical \& Pharmaceutical Bulletin, vol. 41, no. 5, pp. 926-929, 1993.

[106] J. T. Azietaku, H. Ma, X.-A. Yu et al., "A review of the ethnopharmacology, phytochemistry and pharmacology of Notopterygium incisum," Journal of Ethnopharmacology, vol. 202, pp. 241-255, 2017.

[107] H. Tian, Z. Liu, Y. Pu, and Y. Bao, "Immunomodulatory effects exerted by Poria Cocos polysaccharides via TLR4/ TRAF6/NF- $\kappa$ B signaling in vitro and in vivo," Biomedicine \& Pharmacotherapy, vol. 112, p. 108709, 2019.

[108] Y. Sun, "Biological activities and potential health benefits of polysaccharides from Poria cocos and their derivatives," 
International Journal of Biological Macromolecules, vol. 68, pp. 131-134, 2014.

[109] J.-L. Ríos, "Chemical constituents and pharmacological properties ofPoria cocos," Planta Medica, vol. 77, no. 7, pp. 681-691, 2011.

[110] S. R. Lee, S. Lee, E. Moon, H.-J. Park, H. B. Park, and K. H. Kim, "Bioactivity-guided isolation of anti-inflammatory triterpenoids from the sclerotia of Poria cocos using LPS-stimulated Raw264.7 cells," Bioorganic Chemistry, vol. 70, pp. 94-99, 2017.

[111] S.-B. Han, C. W. Lee, L. D. Yoon et al., "Prevention of arthritic inflammation using an oriental herbal combination BDX-1 isolated fromAchyranthes bidentata andAtractylodes japonica," Archives of Pharmacal Research, vol. 28, no. 8, pp. 902-908, 2005.

[112] W. Zheng, X. Lu, Z. Fu et al., "Identification of candidate synovial membrane biomarkers after Achyranthes aspera treatment for rheumatoid arthritis," Biochimica et Biophysica Acta (BBA)-Proteins and Proteomics, vol. 1864, no. 3, pp. 308-316, 2016.

[113] D. Song, Z. Cao, S. Huang et al., "Achyranthes bidentata polysaccharide suppresses osteoclastogenesis and bone resorption via inhibiting RANKL signaling," Journal of Cellular Biochemistry, vol. 119, no. 6, pp. 4826-4835, 2018.

[114] H. Park, H. Lim, H. Kim, and Y. Kwon, "Downregulation of matrix metalloproteinase-13 by the root extract ofCyathula officinalisKuan and its constituents in IL- $1 \beta$-treated chondrocytes," Planta Medica, vol. 77, no. 13, pp. 1528-1530, 2011.

[115] P. Tong, C. Wu, X. Wang et al., "Development and assessment of a complete-detoxication strategy for Fuzi (lateral root of Aconitum carmichaeli) and its application in rheumatoid arthritis therapy," Journal of Ethnopharmacology, vol. 146, no. 2, pp. 562-571, 2013.

[116] S.-S. Liou, I.-M. Liu, M. C. Lai, and J.-T. Cheng, "Comparison of the antinociceptive action of crude Fuzei, the root of Aconitum, and its processed products," Journal of Ethnopharmacology, vol. 99, no. 3, pp. 379-383, 2005.

[117] H. Jin, N. Ma, X. Li, M. Kang, M. Guo, and L. Song, “Application of GC/MS-Based metabonomic profiling in studying the therapeutic effects of Aconitum carmichaeli with ampelopsis japonica extract on collagen-induced arthritis in rats," Molecules, vol. 24, no. 10, p. 1934, 2019.

[118] C. Wang, D. N. Sun, C. F. Liu et al., "Mother root of Aconitum carmichaelii Debeaux exerts antinociceptive effect in Complet Freund's adjuvant-induced mice: roles of dynorpin/ kappa-opioid system and transient receptor potential vanilloid type-1 ion channel," Journal of Translational Medicine, vol. 13, no. 1, 2015

[119] U. T. Gutser, J. Friese, J. F. Heubach et al., "Mode of antinociceptive and toxic action of alkaloids of aconitum spec," Naunyn-Schmiedeberg's Archives of Pharmacology, vol. 357, no. 1, pp. 39-48, 1997.

[120] H. H. Yu, M. Li, Y.-B. Li et al., "Benzoylaconitine inhibits production of IL-6 and IL- 8 via MAPK, Akt, NF- $\kappa$ B Signaling in IL- $1 \beta$-Induced human synovial cells," Biological and Pharmaceutical Bulletin, vol. 43, no. 2, pp. 334-339, 2020.

[121] T. Xu, G. Feng, B. Zhao et al., "A non-target urinary and serum metabolomics strategy reveals therapeutical mechanism of radix astragali on adjuvant-induced arthritis rats," Journal of Chromatography B, vol. 1048, pp. 94-101, 2017.

[122] M. Maresca, L. Micheli, L. Cinci, A. R. Bilia, C. Ghelardini, and L. Di Cesare Mannelli, "Pain relieving and protective effects of Astragalus hydroalcoholic extract in rat arthritis models," Journal of Pharmacy and Pharmacology, vol. 69, no. 12, pp. 1858-1870, 2017.

[123] Y. Qi, F. Gao, L. Hou, and C. Wan, "Anti-inflammatory and immunostimulatory activities of astragalosides," The American Journal of Chinese Medicine, vol. 45, no. 6, pp. 1157-1167, 2017.

[124] B. Wang and M. Z. Chen, "Astragaloside IV possesses antiarthritic effect by preventing interleukin $1 \beta$-induced joint inflammation and cartilage damage," Archives of Pharmacal Research, vol. 37, no. 6, pp. 793-802, 2014.

[125] Z. H. Wang, C. Qin, T. Ran, D. Q. Yang, and J. H. Guo, "Effects of Astragalus glycoprotein on Th17/Treg cells in mice with collagen-induced arthritis," Journal of Biological Regulators and Homeostatic Agents, vol. 32, no. 4, pp. 951957, 2018.

[126] Q. Meng, X. Du, H. Wang, H. Gu, J. Zhan, and Z. Zhou, "Astragalus polysaccharides inhibits cell growth and proinflammatory response in IL-1beta-stimulated fibroblast-like synoviocytes by enhancement of autophagy via PI3K/AKT/ mTOR inhibition," Apoptosis, vol. 22, no. 9, pp. 1138-1146, 2017.

[127] J. B. Jiang, J. D. Qiu, L. H. Yang, J. P. He, G. W. Smith, and H. Q. Li, "Therapeutic effects of astragalus polysaccharides on inflammation and synovial apoptosis in rats with adjuvant-induced arthritis," International Journal of Rheumatic Diseases, vol. 13, no. 4, pp. 396-405, 2010.

[128] H. S. Kang, Y. H. Kim, C. S. Lee, J. J. Lee, I. Choi, and K. H. Pyun, "Anti-inflammatory effects of Stephania tetrandra S. Moore on interleukin-6 production and experimental inflammatory disease models," Mediators of Inflammation, vol. 5, Article ID 952089, 12 pages, 1996.

[129] N. Sekiya, Y. Shimada, A. Niizawa et al., "Suppressive effects of Stephania tetrandra on the neutrophil function in patients with rheumatoid arthritis," Phytotherapy Research, vol. 18, no. 3, pp. 247-249, 2004.

[130] J. H. Lai, "Immunomodulatory effects and mechanisms of plant alkaloid tetrandrine in autoimmune diseases," Acta Pharmacologica Sinica, vol. 23, no. 12, pp. 1093-1101, 2003.

[131] X. S. Yuan, B. Tong, Y. N. Dou, X. Wu, Z. F. Wei, and Y. Dai, "Tetrandrine ameliorates collagen-induced arthritis in mice by restoring the balance between Th17 and Treg cells via the aryl hydrocarbon receptor," Biochemical Pharmacology, vol. 101, pp. 87-99, 2016.

[132] Q. Lv, X. Y. Zhu, Y. F. Xia, Y. Dai, and Z. F. Wei, “Tetrandrine inhibits migration and invasion of rheumatoid arthritis fibroblast-like synoviocytes through down-regulating the expressions of Rac1, Cdc42 and RhoA GTPases and activation of PI3K/Akt and JNK signaling pathways," Chinese Journal of Natural Medicines, vol. 13, no. 11, pp. 831-841, 2015.

[133] W. W. Liu, Y. J. Zhang, W. N. Zhu et al., "Sinomenine inhibits the progression of rheumatoid arthritis by regulating the secretion of inflammatory cytokines and monocyte/ macrophage subsets," Frontiers in Immunology, vol. 9, 2018.

[134] Z. T. Feng, T. Yang, X. Q. Hou et al., "Sinomenine mitigates collagen-induced arthritis mice by inhibiting angiogenesis," Biomedicine \& Pharmacotherapy, vol. 113, p. 108759, 2019.

[135] T. Gao, T. Shi, Z. Wiesenfeld-Hallin, C. I. Svensson, and $\mathrm{X}$. J. Xu, "Sinomenine alleviates mechanical hypersensitivity in mice with experimentally induced rheumatoid arthritis," Scandinavian Journal of Pain, vol. 7, no. 1, pp. 9-14, 2015.

[136] T. Komatsu, S. Katsuyama, F. Takano et al., "Possible involvement of the $\mu$ opioid receptor in the antinociception 
induced by sinomenine on formalin-induced nociceptive behavior in mice," Neuroscience Letters, vol. 699, pp. 103$108,2019$.

[137] X. Qian, Z. Zhao, W. Shang, Z. Xu, B. Zhang, and H. Cai, "Serum proteomic analysis of the antiarthritic effects of sinomenine on rats with collageninduced arthritis," Molecular Medicine Reports, vol. 18, no. 1, pp. 49-58, 2018.

[138] Y. Wang, C. D. Yu, and H. Y. Zhang, "Lipopolysaccharidesmediated injury to chondrogenic ATDC5 cells can be relieved by Sinomenine via downregulating micro RNA-192," Phytotherapy Research, vol. 33, no. 7, pp. 1827-1836, 2019.

[139] X.-X. Zhao, C. Peng, H. Zhang, and L.-P. Qin, "Sinomenium acutum: a review of chemistry, pharmacology, pharmacokinetics, and clinical use," Pharmaceutical Biology, vol. 50, no. 8, pp. 1053-1061, 2012.

[140] W. Liu, X. Qian, W. Ji, Y. Lu, G. Wei, and Y. Wang, "Effects and safety of Sinomenine in treatment of rheumatoid arthritis contrast to methotrexate: a systematic review and meta-analysis," Journal of Traditional Chinese Medicine, vol. 36, no. 5, pp. 564-577, 2016.

[141] S. Parker, B. May, C. Zhang, A. L. Zhang, C. Lu, and C. C. Xue, "A pharmacological review of bioactive constituents of Paeonia lactiflora Pallas and Paeonia veitchii Lynch," Phytotherapy Research, vol. 30, no. 9, pp. 1445-1473, 2016.

[142] Z. Feng, J. Xu, G. He et al., "The efficacy and safety of the combination of total glucosides of peony and leflunomide for the treatment of rheumatoid arthritis: a systemic review and meta-analysis," Evidence-Based Complementary and Alternative Medicine, vol. 2016, Article ID 9852793, 8 pages, 2016.

[143] J. Luo, D.-E. Jin, G.-Y. Yang et al., "Total glucosides of paeony for rheumatoid arthritis: a systematic review of randomized controlled trials," Complementary Therapies in Medicine, vol. 34, pp. 46-56, 2017.

[144] J. Bao and S.-M. Dai, "A Chinese herb Tripterygium wilfordii Hook F in the treatment of rheumatoid arthritis: mechanism, efficacy, and safety," Rheumatology International, vol. 31, no. 9, pp. 1123-1129, 2011.

[145] J. Wang, N. Chen, L. Fang et al., “A systematic review about the efficacy and safety of Tripterygium wilfordii Hook.f. preparations used for the management of rheumatoid arthritis," Evidence-Based Complementary and Alternative Medicine, vol. 2018, Article ID 1567463, 13 pages, 2018.

[146] Y. Liu, S. Tu, W. Gao et al., "Extracts of Tripterygium wilfordii Hook F in the treatment of rheumatoid arthritis: a systemic review and meta-analysis of randomised controlled trials," Evidence-Based Complementary and Alternative Medicine, vol. 2013, Article ID 410793, 11 pages, 2013.

[147] H. L. Wang, Q. Jiang, X. H. Feng et al., "Tripterygium wilfordii Hook $\mathrm{F}$ versus conventional synthetic disease-modifying anti-rheumatic drugs as monotherapy for rheumatoid arthritis: a systematic review and network meta-analysis," BMC Complementary and Alternative Medicine, vol. 16, no. 1, 2016.

[148] T. Rodrigues, D. Reker, P. Schneider, and G. Schneider, "Counting on natural products for drug design," Nature Chemistry, vol. 8, no. 6, pp. 531-541, 2016.

[149] M. Wink, "Evolutionary advantage and molecular modes of action of multi-component mixtures used in phytomedicine," Current Drug Metabolism, vol. 9, no. 10, pp. 996-1009, 2008.

[150] Z. Bian, S. Chen, C. Cheng, J. Wang, H. Xiao, and H. Qin, "Developing new drugs from annals of Chinese medicine," Acta Pharmaceutica Sinica B, vol. 2, no. 1, pp. 1-7, 2012. 